\title{
DFF40-iRGD, As A Novel Chimeric Protein With Efficient Cytotoxic and Apoptotic Effects Against Triple-Negative Breast Cancer Cells
}

\section{Raheleh Amrollahi-nia}

Isfahan University of Medical Sciences

Vajihe Akbari

Isfahan University of Medical Sciences

Fatemeh Shafiee ( $\square$ f_shafiee@pharm.mui.ac.ir)

Isfahan University of Medical Sciences https://orcid.org/0000-0001-6484-1931

\section{Research Article}

Keywords: DNA fragmentation factor, internalizing RGD, Breast cancer, Apoptosis

Posted Date: July 6th, 2021

DOI: https://doi.org/10.21203/rs.3.rs-618195/v1

License: (c) (1) This work is licensed under a Creative Commons Attribution 4.0 International License.

Read Full License 


\section{Abstract \\ Purpose}

DNA fragmenting factor (DFF40), an endonuclease inducing irreversible apoptosis protein, is downregulated in many types of tumor cells. iRGD is a tumor-penetrating peptide with high affinity to cancer cells overexpressing $a_{\mathrm{v}} \beta_{3}$ receptors. The aim of this study was to produce the recombinant DFF40-iRGD protein as a new molecule to selectively induce cytotoxicity in cancer cells and to evaluate its biological effects.

\section{Methods}

The three-dimensional structure of DFF40-iRGD was predicted using Modeller software and its interaction with $a_{v} \beta_{3}$ receptor was evaluated by HADDOCK web-server. Recombinant DFF40 and DFF40-iRGD proteins were produced using intein fusion system in Escherichia coli BL21 (DE3). To improve the soluble expression, the inducer concentration, temperature and incubation time were optimized. After purification of DFF40 and DFF40-iRGD using chitin column, the cytotoxic and apoptotic effects of the proteins against MDA-MB-231 ( $a_{v} \beta_{3}$ positive) and MCF-7 ( $a_{v} \beta_{3}$ negative) cell lines were evaluated using cell viability assay and flow cytometric analysis.

\section{Results}

The results of molecular docking indicated the proper interaction of DFF40-iRGD with the integrin receptor comparable to iRGD. The optimum conditions of soluble expression of proteins were the induction with $0.5 \mathrm{mM}$ and $0.1 \mathrm{mM}$ of IPTG for DFF40 and DFF40-iRGD, respectively, at $7^{\circ} \mathrm{C}$ for 24 hours. After 48 hours of incubation, DFF40-iRGD exhibited significantly higher cytotoxic effect against MDA-MB-231 cells than MCF-7 cells as $I_{50}$ values of 0.77 and $1.64 \mu \mathrm{g} / \mathrm{ml}$ were found for MDA-MB-231 and MCF-7 cells, respectively. However, DFF40 cytotoxicity was not significantly different in two cell lines. Furthermore, Flow cytometry results showed that the fusion protein can induce remarkably apoptotic cell death in cancer cells.

\section{Conclusion}

in this study, DFF40-iRGD protein was produced in soluble form and its inhibitory effects on cancer cell survival and induction of apoptosis were demonstrated; therefore, it has the potential to be used as a drug candidate for targeted treatment of breast cancer, especially Triple Negative Breast Cancer Cells.

\section{Introduction}


Breast cancer is the most prevalent malignances among women around the world. Every year, about 1.7 million of new breast cancer cases are diagnosed (Rojas K et al. 2016; Winters S et al. 2017). Chemotherapeutic agents, as the most common treatment approach for breast cancer, cause severe adverse effects mainly due to its cytotoxic effect on healthy cells, as well as cancer cells (Tao Z et al. 2015). One of the novel biological agents currently evaluated for cancer treatment is apoptosis-inducing molecules. DNA Fragmentation Factor (DFF), a heterodimer protein including two subunits DFF40 and DFF45, is one of the most interesting ones. DFF40, a magnesium-dependent factor with $40 \mathrm{kDa}$ molecular weight and 338 amino acid residues, creates double strand breaks at the 3'-OH ends of DNA (Jijie Gu et al. 1999). It was shown that the expression level of DFF40 and its DNA fragmentation activity decreased in glioblastoma which highlights its role in poor prognosis and resistance to treatment for this type of cancer (Sánchez-Osuna et al. 2016).

Till now, two chimeric proteins containing DFF40 were produced by recombinant DNA technology and their ability to induce apoptosis in cancer cells was evaluated. First, DFF40 was fused to GnRH to target the colonic adenocarcinoma cells (Ben-Yehudah et al. 2003). The results of this study showed that this protein acts as an apoptosis trigger and decreases in the S-phase population. Also, in vivo experiments showed a reduction in tumor weight of colon adenocarcinoma for xenograft mice received this recombinant protein (Ben-Yehudah et al. 2003). In another study, a DFF40 was fused to GM-CSF as the targeting moiety and expressed in E. coli to target acute myeloid leukemia. Cytotoxic experiments indicated that this fusion protein can induce apoptosis in a selective and concentration-dependent manner (Mathew et al. 2013).

So, DFF40 is a highly toxic protein which affects cancer cells and increases their death rates. However, to exert specific effect on cancer cells, a targeting moiety is required to recognize over-expressed surface receptors of tumor cells. Among these receptors integrins, especially $a_{v} \beta_{3}$ and $a_{v} \beta_{5}$, are highly interesting molecules due to their critical roles in cell adhesion process and signaling pathways, ultimately results in cells reproduction and survival (Cruet-Hennequart et al. 2003). Therefore, it seems that these receptors are potential targets for cancer diagnosis and treatment.

RGD (Arg-Gly-Asp) which is recognized by integrin receptors, is a tripeptide motif with great affinity for integrin receptors (Liu et al. 2019). Until now, several fusion proteins containing RDG have been developed. For instance, (RGD)3/tTF was constructed as a fusion protein for the treatment of tumor blood vessels via selective thrombosis and showed proper binding capacity with $a_{\mathrm{v}} \beta_{3}$ receptors (JiangHua et al. 2007). In another study, researchers assessed antitumor effects of IFN-a2a-RGD fusion protein expressed in E. coli. They demonstrated that this new recombinant protein had firmly attached to the $a_{V} \beta_{3}$ receptors and revealed beneficial effects as a targeting agent for cancer cells (Wen et al. 2017). However, this motif only can transfer anticancer and diagnostic agents to the cell surfaces without ability to enter the cancer cells (Danhier et al. 2012). In another word, RGD motif acts as a concentrator for chemotherapeutic agents on cancer cell's surfaces as well as in tumor tissues. 
For the first time, Sugahara et al, (2009) introduced a type of RGD, named internalizing RGD (iRGD), which can enter the cancer cells. This peptide (CRGDK/RGPD/EC) contains RGD motif with the attachment ability to $\mathrm{aV}_{3}$ integrins. After the accumulation, the peptide is enzymatically cleaved by cell surface associated protease and makes CendR (C-end Rule) motif. The truncated motif (CRGDK/R) has a Cterminal exposure and can penetrate cells by attaching to neuropilin-1 (NRP-1) with a high cell-surface density on cancer cells (Sugahara et al. 2010). So, the current study was aimed to express and purify a novel fusion protein of DFF40-iRGD in E. coli for the targeted therapy of tumors with high level expression of $a_{v} \beta_{3}$ receptors.

\section{Materials \& Method}

\section{1-Prediction the three-dimensional structure of DFF40-iRGD}

In order to design and produce the proper chimeric protein, the 3D structure of DFF40-iRGD was predicted by Modeller 9.24 with $2.60 \mathrm{~A}^{\circ}$ crystal structure of wild-type Caspase-activated DNase (PDB id: 1VOD) for DFF-40 and solution structure of an RGD peptide isomer-A (PDB id: 1FUV) for iRGD, as the best templates. Then, the interaction assessment with integrin receptor was performed using HADDOCK web-server after predicting the 3D structure of $\beta 3$ receptor sub-unit with $3.10 \mathrm{~A}^{\circ}$ crystal structure of the extracellular segment of integrin aV $\beta 3$ (PDB id: 1JV2) as the most suitable template. Visualization of each PDB was performed by PyMol software in each stage.

\section{2-Cloning and soluble expression of DFF40-iRGD}

The coding sequence of DFF40 and DFF40 fused to iRGD motif sequence was optimized based on E. coli codon usage and after chemical synthesis was commercially sub-cloned into pTWIN-1 vector (New England BioLabs, Massachusetts, USA) by BioMatik Company (Canada). E. coli BL21 (DE3) competent cells were transformed with pTWIN1-DFF40 and pTWIN1-DFF40-iRGD via heating shock procedure. A single positive colony was cultured in Luria-Bertani (LB) broth medium containing $100 \mu \mathrm{g} / \mathrm{ml}$ ampicillin and after reaching the logarithmic phase, the expression of protein was induced by addition of isopropyl$\beta$-D-thiogalactosid (IPTG). Soluble protein expression was optimized by Response Surface Methodology (RSM) using Design-Expert software (version 8.0.7.1, StatEase Inc., Minneapolis, USA) based on three independent variables including inducer concentration, post-induction time and incubation temperature. In each step, $12 \%$ SDS-PAGE was used to measure the expression level of recombinant proteins in comparison to a known concentration of Human serum albumin (Octapharma, Sweden), quantified by GelAnalyzer software.

\section{3-Purification of fusion protein}

IMPACT $^{\text {TM }}$ purification system (New England BioLabs, Massachusetts, USA) was used for the recombinant protein purification. Based on $\mathrm{N}$-terminus cloning, self-cleavage activity of intein 1 was induced by changing pH level from 8.5 to 6.5. First, cellular pellet was re-suspended in B1 buffer (Tris- $\mathrm{HCl} 20 \mathrm{mM}$, $\mathrm{NaCl} 500 \mathrm{mM}$ and EDTA $1 \mathrm{mM}, \mathrm{pH}$ 8.5) and lysed with ultra-sonication on ice followed by $15 \mathrm{~min}$ of 
centrifugation at $7000 \times g$ and $10^{\circ} \mathrm{C}$. Then, the supernatant including soluble protein was transferred to the chitin resin column. In the last stage, B2 buffer (Tris- $\mathrm{HCl} 20 \mathrm{mM}, \mathrm{NaCl} 500 \mathrm{mM}$ and EDTA $1 \mathrm{mM}$, Triton $\mathrm{x}-1000.3 \%$, Tween $200.2 \%$, pH 6.5) was used to induce intein 1 self-cleavage activity after the incubation at room temperature for 24 hours and the column contents were collected and evaluated by SDS-PAGE.

\section{4-Sample preparation for in vitro assay}

In order to replace B2 buffer with PBS, 16 -hour dialysis was performed at $4^{\circ} \mathrm{C}$ with cellulose dialyze membrane. Every one hour for three times, PBS buffer was replaced by a new one. Finally, Bradford's method with Human serum albumin as a standard was used to determine the protein concentration and sterilization was performed using $0.22 \mu \mathrm{m}$ membrane filters.

\section{6-Biological assays}

\subsection{1-MTT assay}

In vitro cytotoxic effects evaluation of recombinant proteins on MDA-MB-231 (as $a_{v} \beta_{3}$ receptor positive cells) and MCF-7 (as cells without overexpressing of $a_{v} \beta_{3}$ receptors) was performed by MTT ([3-(4,5dimethylthiazol-2-yl)-2,5-diphenyltetrazolium bromide]) assay. The cells were cultured in Roswell Park Memorial Institute medium (RPMI) 1640 enriched by $10 \%$ (v/v) fetal bovine serum (FBS) and antibiotics (100 IU/mL penicillin and $100 \mu \mathrm{g} / \mathrm{mL}$ streptomycin) at $37^{\circ} \mathrm{C}$ in a $5 \% \mathrm{CO}_{2}$ incubator. To evaluate the cytotoxicity of DFF40-iRGD and DFF40, $180 \mu$ l of RPMI 1640 medium containing $3 \times 10^{4}$ cells $/ \mathrm{ml}$ of each cells was added to the wells of a 96-well microplate and incubated for 24 hours at $37^{\circ} \mathrm{C}$. The next day, different concentrations $(0.25,0.5,1,2$ and $4 \mu \mathrm{g} / \mathrm{ml})$ of DFF40-iRGD or DFF40 was added to wells and incubated at $37^{\circ} \mathrm{C}$ for 24,48 or 72 hours. Then, $20 \mu$ of MTT solution $(5 \mathrm{mg} / \mathrm{ml})$ was added to each wells and incubated for 3 other hours. Finally, well contents were replaced by $150 \mu \mathrm{l}$ of dimethyl sulfoxide (DMSO) to dissolve formazan crystals and the absorbance was measured at $570 \mathrm{~nm}$ by a microplate reader (Bio-Rad, USA).

\subsection{2- Flow cytometry}

For the apoptosis assessment of DFF40-iRGD, about $5 \times 10^{5} \mathrm{cells} / \mathrm{ml}$ of MDA-MB-231 were seeded in 6well microplate and incubated at $37^{\circ} \mathrm{C}$ overnightly. Then, cells were incubated with 0.25 and $0.5 \mu \mathrm{g} / \mathrm{ml}$ of fusion protein at $37^{\circ} \mathrm{C}$ for 24 hours and flow cytometry analysis was conducted to evaluate the apoptotic cell death. Briefly, all contents of each well were pulled out, the cells were washed and collected. Then, cells were incubated with annexin-V- FLUS for 30 minutes under dark conditions according to the Kit manufacturer manual (eBioscience ${ }^{\mathrm{TM}}, \mathrm{US}$ ). Again, the cells were centrifuged at $300 \times g$ followed by washing with Binding buffer (1X) and then they were re-suspended in $200 \mu \mathrm{l}$ of Binding buffer (1X). Finally, propidium iodide was added to the flow cytometery tubes and analyzed on a BD FACS Calibur (BD, USA). 


\section{7-statistical analysis}

Each experiment was performed in triplicate to ensure accuracy and reproducibility of data. SPSS Ver. 25 software was used for the comparison of Mean \pm SD parameter between treated groups. Analysis of variance (ANOVA) followed by Post-Hoc statistical tests was used to identify differences between groups. The significance was contemplated as $\mathrm{P}<0.05$. Finally, the cell survival percent against concentration was drawn by GraphPad Prism 7.0 software to determine the IC50 of each recombinant protein.

\section{Results}

\section{1-Homology modeling and docking}

Among 1000 predicted models for iRGD by Modeller 9.24, the best one with minimum DOPE (Discrete Optimized Protein Energy) score of -233.67093 and molpdf of 42.24848 and maximum GA-341 of 0.66843 was selected for molecular docking with beta 3 subunit of receptor. For $\beta 3$ receptor, on the other hand, these parameters were reported as -44668.96094 for DOPE score, 5939.67969 for molpdf, and 0.29372 for GA-341. Interaction of DFF40-iRGD with $\beta 3$ receptor analyzed by HADDOCK confirmed that the presence of DFF-40 next to the iRGD, does not reduce its interaction with integrin receptor. Docking results given in Table 1 demonstrate stronger interaction for DFF40-iRGD than native iRGD.

Table 1

HADDOCK results of molecular docking

\begin{tabular}{|lll|}
\hline Parameters & $\begin{array}{l}\text { Beta3/DFF40-iRGD } \\
\text { Complex }\end{array}$ & $\begin{array}{l}\text { Beta3/iRGD } \\
\text { Complex }\end{array}$ \\
\hline HADDOCK score & $-160.6 \pm 7.1$ & $-140.6 \pm 9.7$ \\
\hline Cluster size & 228 & 38 \\
\hline RMSD & $0.8 \pm 0.5$ & $0.5 \pm 0.3$ \\
\hline E $_{\text {inter }}{ }^{a}$ & -362 & -436.1 \\
\hline Evdw $^{b}$ & $-61.1 \pm 4.4$ & $-33 \pm 2.2$ \\
\hline Elec $^{c}$ & $-300.9 \pm 60.5$ & $-403.1 \pm 21.7$ \\
\hline Edesolv ${ }^{\text {d }}$ & $-66.2 \pm 9.4$ & $48.5 \pm 7.3$ \\
\hline E $_{\mathrm{rv}}{ }^{\text {e }}$ & $268.7 \pm 39.03$ & $215.4 \pm 46.42$ \\
\hline BSA $^{f}$ & $1978.1 \pm 64.6$ & $1324.7 \pm 52.6$ \\
\hline Z-Score $^{\text {f }}$ & -1.4 & -1.1 \\
\hline
\end{tabular}

Page 6/16 
a Intermolecular energy: sum of the van der waals and electrostatic energies.

b Van der Waals energy

c Electrostatic energy

d Desolvation energy

e Restrain violation energy

f Total BSA: Buried surface energy

\section{2-Expression and purification of DFF40 and DFF40-iRGD}

SDS-PAGE analysis confirmed the expression of DFF40 and DFF40-iRGD fused to intein 1 with $66 \mathrm{kDa}$ and $67 \mathrm{kDa}$ bands, respectively (Fig. 1). The optimum condition for soluble expression of DFF40 was determined as $0.5 \mathrm{mM}$ of IPTG, at $7{ }^{\circ} \mathrm{C}$ for 24 hours. The best condition for soluble expression of DFF40iRGD was found to be $0.1 \mathrm{mM}$ of inducer, incubation at $7^{\circ} \mathrm{C}$ and for 24 hours. After the induction of cleavage of intein from the recombinant proteins, a band approximately at 39 and $40 \mathrm{kDa}$ (corresponding to DFF40 and DFF40-iRGD, respectively), was observed (Fig. 2) proving successful purification with IMPACT system. Finally, according to the Bradford method the yield of purified soluble proteins was calculated as 477.5 and $256.76 \mu \mathrm{g}$ per litter of bacterial culture for DFF40 and DFF40-iRGD, respectively.

\section{3-MTT assay}

As shown in Fig. 3a, both proteins exhibited cytotoxic effects on both MCF-7 and MDA-MB-231 cell lines in concentration and time-dependent manners.

A significant difference between the cytotoxicity of DFF40 and DFF40-iRGD proteins in the similar concentrations was observed for MDA-MB-231 cell line which has high expression levels of $a_{v} \beta_{3}$ receptors. The highest difference in cytotoxicity was obtained at a concentration of $0.25 \mu \mathrm{g} / \mathrm{ml}$ for all times (P-value $<0.001)$. Over the time, the cytotoxic effects of both recombinant proteins increased. However, after 72 hours, difference between the cytotoxic effects of the two recombinant proteins was less than those obtained after 48 and 24 hours.

Results of MTT assay for MCF-7 cell line showed that the cytotoxic effects of two recombinant proteins were enhanced by increasing the concentration.

After 24 hours, a significant difference in cytotoxicity was observed between the two recombinant proteins, at concentration equal or greater than $1 \mu \mathrm{g} / \mathrm{ml}$. After 48 hours of treatment, a significant difference was observed between the cell survival of two recombinant proteins at concentrations of 2 and $4 \mu \mathrm{g} / \mathrm{ml}$. Finally, in 72-hour treatments, statistical evaluation of the results showed that there was a significant difference between the cytotoxic effects of these two proteins at concentrations of $1 \mu \mathrm{g} / \mathrm{ml}$ and above (Fig. 3b). 
Finally, by drawing the cell survival percentage curves in terms of concentration for the two cell lines MDA-MB-231 and MCF-7, the IC50 concentrations of the two proteins were obtained, which are reported in Table 2. As expected, the IC50 for each protein decreases over time, and the difference between the two proteins in a cell line decreases at similar times.

Table 2

IC50 values of proteins in different cell lines and at different times

\begin{tabular}{|llll|}
\hline $\begin{array}{l}\text { Cell line } \\
\text { Protein/Time }\end{array}$ & Incubation Time & MDA-MB-231 & MCF-7 \\
\hline DFF40 & $24 \mathrm{~h}$ & $3.01 \mu \mathrm{g} / \mathrm{ml}$ & $2.44 \mu \mathrm{g} / \mathrm{ml}$ \\
\cline { 2 - 4 } & $48 \mathrm{~h}$ & $\mu \mathrm{g} / \mathrm{ml} 1.96$ & $\mu \mathrm{g} / \mathrm{ml} 2.56$ \\
\cline { 2 - 4 } & $72 \mathrm{~h}$ & $1.05 \mu \mathrm{g} / \mathrm{ml}$ & $1.46 \mu \mathrm{g} / \mathrm{ml}$ \\
\hline DFF40-iRGD & $24 \mathrm{~h}$ & $1.67 \mu \mathrm{g} / \mathrm{ml}$ & $2.00 \mu \mathrm{g} / \mathrm{ml}$ \\
& $48 \mathrm{~h}$ & $\mu \mathrm{g} / \mathrm{ml} 0.77$ & $\mu \mathrm{g} / \mathrm{ml} 1.64$ \\
& $72 \mathrm{~h}$ & $0.61 \mu \mathrm{g} / \mathrm{ml}$ & $0.92 \mu \mathrm{g} / \mathrm{ml}$ \\
\hline
\end{tabular}

\section{4-Evaluation of apoptosis induction for DFF40-iRGD on MDA-MB-231 cells}

Evaluation of apoptosis of MDA-MB-231 cells treated with concentrations of 0.25 and $0.5 \mu \mathrm{g} / \mathrm{ml}$ of DFF40-iRGD for 24 hours, indicates an increase in cell apoptosis by increasing the protein concentration. The results of flow cytometry analysis are shown in Fig. 4. In the control group, 95\% of the cells survived and only $4.7 \%$ of them had apoptosis; While in the group treated with a final concentration of $0.25 \mu \mathrm{g} / \mathrm{ml}$ of the chimeric protein, $31 \%$ of the cells survived and $64 \%$ were in the early and late apoptosis stages; However, in the treatment of cells with DFF40-iRGD with a final concentration of $0.5 \mu \mathrm{g} / \mathrm{ml}, 24 \%$ of cells survived and $76 \%$ developed apoptosis (Fig. 4).

\section{Discussion}

Especially, the migrations of tumor cells and their aggressive phenotypes is associated with av $\beta 3$ related signaling (Hamidi et al. 2016). Furthermore, enhanced av $\beta 3$ expression have been showed to promote the growth of breast cancer cells and metastasis to bone (Takayama et al. 2005). So, these receptor, overexpressed on the several cancer cells not normal body cells, and involved in invading the tumor cells, are attractive approach to targeted delivery of therapeutic agents to cancer cells. In the design of fusion protein, because the iRGD moiety must have a free CendR terminus, we had to put it at the C-terminal of DFF40 protein. On the other hand, because of the greater effect of $\beta 3$ in the binding of RGD peptide than the other sub-unit (Garrigues et al. 2008), $\beta 3$ was used for molecular docking. The results of protein 
docking with the receptor in HADDOCK indicate that binding of the DFF40 protein to the iRGD peptide not only prevents exposure and binds to the $a_{v} \beta_{3}$ integrin receptor, but also results in a more stable structure.

In the expression stage, it is an established remark that post-induction temperature and inducer concentration are the most important factors influencing the expression level of proteins. In general, lowering the post-induction temperature can reduce inclusion body formation by reducing the expression of the proteins (Vasina et al. 1997). In a study by San-Miguel et al. E. coli BL21 (DE3) was used for the expression of Progesterone $5 \beta$-reductase, showed that only proteins expressed at $15^{\circ} \mathrm{C}$ and below are in active form (San-Miguel et al. 2013). So, lowering the temperature as well as inducer concentration led to reduce the speed of protein expression and finally, increased the soluble protein level (de Groot et al. 2006).

The results of Design-Expert software showed a significant effect of temperature on the soluble expression of both proteins; this factor has the greatest effect on the soluble expression of DFF40 and DFF40-iRGD; a few increasing in temperature, led to a significant decrease in the expression in protein soluble form. In addition, the results indicated that the incubation period had the least effect compared to other independent variables according to the Design-Expert software results.

In general, the addition of inducer in low amounts (IPTG used in our study) results in insufficient induction and consequently low expression of the recombinant protein; while adding extra amounts of these expensive inducers, in addition to wasting costs, can lead to toxic effects on cell growth (Ramirez et al. 1994).

The results of this study showed that increasing the concentration of IPTG in the induction of DFF40 protein increases the expression of soluble and insoluble proteins; while the highest expression of DFF40iRGD protein in soluble form was observed in the lowest inducer concentration $(0.1 \mathrm{mM})$ and increasing IPTG concentration led to the increased insoluble expression and consequently increased inactive protein content.

The purification technique using the intein system has been used to produce various recombinant proteins. For example, human GM-CSF was produced and purified by its fusing with the intein in the pTYB11 vector (Goffe et al. 2003). In a study conducted by Wang, Parathyroid hormone was also cloned into the pTXB1 vector and purified using the IMPACT system by adding DTT (Wang et al. 2007). In two these studies, reducing agents, especially dithiotritol, have been used to induce the self-cleavage properties of intein. The addition of this chemical, in addition to increasing the cost of large-scale purification, allows the three-dimensional structure of disulfide-containing proteins to be modified by reducing these bonds, while the use of intein-1 in pTWIN1 vector and induction the self-cleavage property of intein by $\mathrm{pH}$ change, is more logical and convenient.

For the first fusion protein containing DDF40, GM-CSF-DFF40, cytotoxicity was confirmed at $200 \mathrm{nM}$ of this protein against THP-1 cells, indicating a high potency of this protein in inducing cell apoptosis. Also, the rate of apoptosis of cells treated with $200 \mathrm{nM}$ of GM-CSF-DFF40 by Annexin V-FITC staining kit 
showed $30-35 \%$ of apoptosis in this cell line (Mosrati et al. 1993). However, in our study, the calculated IC50 of DFF40-iRGD was determined as $15 \mathrm{nM}$ after 72 hours of treatment can be attributed to the more efficient internalizing efficacy of this fusion protein than GM-CSF-DFF40. Furthermore, the rate of apoptosis due to treatment of MDA-MB-231 cells with a concentration of $0.5 \mu \mathrm{g} / \mathrm{ml}$ (near to the concentration of IC50) of DFF40-iRGD was equal to $76 \%$, which well Confirms the apoptosis inducing effects of this protein on integrin receptor positive tumor cells. These apoptosis inducing effects of DFF40 was also confirmed in our pervious study on B16 cell transfected with a recombinant pCDNA vector containing the DFF40 gene under the control of Survivin promoter (minayian et al. 2021).

For GnRH-DFF40 fusion protein, on the other hand, apoptosis induction was established by the DNA fragmentation assay and increasing in the caspase 3 and 9 activity, especially after 24 hours of the treatment of colo 205 colon carcinoma cell line (Ben-Yehudah et al. 2003). These results indicated that treatment for 24 hours can successfully induce apoptosis in the tumor cells.

For iRGD peptide, used in the present as the targeting moiety, there are several similar designed molecules. In the study of Zhang et al. (2016), the concomitant use of the iRGD peptide with cetuximab (Erbitux $\left.{ }^{\circledR}\right)$ was proposed as a new strategy for the treatment of Non-Small-Cell Lung Cancer (NSCLC). In this study, A549 cells were used with the high expression levels of $a_{v} \beta_{3}, a_{v} \beta_{5}$ and NRP-1 receptors. The results of this study showed a significant increase in the apoptotic index of cells treated with coadministration of Erbitux ${ }^{\circledR}$ and iRGD peptide due to more cell penetration. Also, this simultaneous use in xenograft mice reduced the weight and size of the induced tumor. A 2019 study by Yang et al. (2019) for IL-24-iRGD fusion protein on the same cell line showed similar results in the treatment of NSCLC lung cancer. In the mentioned study, IL24-iRGD induced apoptosis after 48 hours of exposure to the A549 cells. While in the same concentrations, the apoptotic effect of native IL-24 was negligible. Again, these data confirmed that more cytotoxic effects of DFF40-iRGD in comparison to the native DFF-40, refer to the presence of iRGD in its structure led to more penetration ability to aV $\beta 3$ positive cells (MDA-MB-231). Furthermore, it may be possible to observe more apoptotic effects by increasing the treatment time.

For the MCF-7 cells, we used as a negative control cell line and assumed with low level of $\mathrm{aV}_{3}$ integrin receptor, we observed some significant cytotoxicity especially with increasing the time of incubation. This toxicity may be related to the non-receptor mediated endocytosis for native form of DFF40, as shown for the treated MDA-MB-231 cells, as well as interaction of iRGD with other related integrin receptor sub-types presented on the surface of this cell line (Yan et al. 2016) .

\section{Conclusion}

In this study, we reported successful expression and purification of the DFF40-iRGD fusion protein using intein fusion system in E. coli. Biological evaluation on two breast cancer cell lines using MTT assay and flow cytometry analysis suggested selective cytotoxicity of this fusion protein mainly through apoptotic cell death induction. Thus, the DFF40-iRGD protein can be considered as a new candidate in the 
treatment of various cancers, especially breast cancer. However, further in vitro and in vivo evaluations are still required to confirm the efficacy and safety this novel fusion protein.

\section{Declarations}

\section{Ethical Approval and Consent to participate}

This article does not contain any studies with human participants or animals performed by any of the authors. The Ethics Committee of Isfahan University of Medical Sciences approved this research with the code of IR.MUI.RESEARCH.REC IR.1398.355.

\section{Consent for publication}

All authors are agree for publication this manuscript.

\section{Availability of supporting data}

The data is available and present according to the reviewer and editor comment.

\section{Competing interests}

There is no conflict of interest.

\section{Funding}

The content of this paper was extracted from the Pharm. D thesis submitted by Raheleh Amrollahi-nia which was financially supported by Research Deputy of Isfahan University of Medical Sciences, with Grant No. 398454.

\section{Authors' contributions}

Raheleh Amrollani-nia performed the experimental and wrote the first version of the manuscript, Vajihe Akbari revised the manuscript, Fatemeh Shafiee designed the experimental, analyzed the data and revised the manuscript.

\section{Acknowledgements}

Authors would like to appreciate valuable technical assistance of laboratory experts in molecular Biotechnology and cell culture labs.

\section{References}

1. Ben-Yehudah A, Aqeilan R, Robashkevich D, Lorberboum-Galski H (2003) Using apoptosis for targeted cancer therapy by a new gonadotropin releasing hormone-DNA fragmentation factor 40 chimeric protein. Clin Can Res. 9:1179-89. 
2. Cruet-Hennequart S, Maubant S, Luis J, Gauduchon P, Staedel C, Dedhar S (2003) a v integrins regulate cell proliferation through integrin-linked kinase (ILK) in ovarian cancer cells. Oncogene. https://doi.org/10.1038/sj.onc.1206347

3. Garrigues HJ, Rubinchikova YE, DiPersio CM, Rose TM (2008) Integrin aV $\beta 3$ binds to the RGD motif of glycoprotein B of Kaposi's sarcoma-associated herpesvirus and functions as an RGD-dependent entry receptor. J Virol. https://doi.org/10.1128/jvi.01673-07

4. Guimarais V, Velasco R, Plans G, Vidal N, Tortosa A, Barcia C (2016) An intrinsic DFF40/CAD endonuclease deficiency impairs oligonucleosomal DNA hydrolysis during caspase-dependent cell death: a common trait in human glioblastoma cells. Neuro-oncology. https://doi.org/10.1093/neuonc/nov315. Epub 2016 Jan 10

5. Hamidi H, Pietila M, Ivaska J (2016) The complexity of integrins in cancer and new scopes for therapeutic targeting. Br J Can. https://doi.org/10.1038/bjc.2016.312

6. Jiang-Hua YA, Gui-Wang YA, Jie-Ping WA, Na WU, Zhuang GH (2007) Gene expression and activity analysis of a novel fusion protein (RGD) 3/tTF. Chin J Biotechnol. https://doi.org/10.1016/S18722075(07)60032-6

7. Jijie Gu, Rui-Ping Dong (1999) Functional Interaction of DFF35 and DFF45 with Caspase-activated DNA Fragmentation Nuclease DFF40. J Biol Chem. https://doi.org/10.1074/jbc.274.30.20759

8. Liu J, Yuan S, Wang L, Sun X, Hu X, Meng X, Yu J (2019) Diagnostic and Predictive Value of Using RGD PET/CT in Patients with Cancer: A Systematic Review and Meta-Analysis. BioMed Res Int. https://doi.org/10.1155/2019/8534761

9. Mathew M, Zaineb KC, Verma RS (2013) GM-CSF-DFF40: a novel humanized immunotoxin induces apoptosis in acute myeloid leukemia cells. Apoptosis. https://doi.org/10.1007/s10495-013-0840-8

10. Minaiyan G, Shafiee F, Akbari V. Survivin Promoter-Driven DFF40 Gene Expression Sensitizes Melanoma Cancer Cells to Chemotherapy. Int J Toxicol. 2021; https://doi.org/10.1177/10915818211014170

11. Mosrati R, Nancib N, Boudrant J (1993) Variation and modeling of the probability of plasmid loss as a function of growth rate of plasmid-bearing cells of Escherichia coli during continuous cultures. Biotechnol Bioengineer. https://doi.org/10.1002/bit.260410402

12. Ramirez O, Zamora R, Espinosa G, Merino E, Bolivar F, Quintero R (1994) Kinetic study of penicillin acylase production by recombinant $\mathrm{E}$. coli in batch cultures. Proc Biochem. https://doi.org/10.1016/0032-9592(94)85004-6.

13. Rojas K, Stuckey A (2016) Breast cancer epidemiology and risk factors. Clin Obst Gynecol. https://doi.org/10.1097/GRF.0000000000000239

14. Sánchez-Osuna M, Martínez-Escardó L, Granados-Colomina C, Martínez-Soler F, Pascual-Guiral S, Iglesias-

15. Danhier F, et al (2012) RGD-based strategies to target alpha (v) beta (3) integrin in cancer therapy and diagnosis. Mol Pharma. https://doi.org/10.1021/mp3002733. Epub 2012 Oct 4 
16. Sugahara KN, Teesalu T, Karmali PP, Kotamraju VR, Agemy L, Girard OM, et al (2009) Tissuepenetrating delivery of compounds and nanoparticles into tumors. Can Cel. https://doi.org/10.1016/j.ccr.2009.10.013

17. San-Miguel T, Pérez-Bermúdez P, Gavidia I (2013) Production of soluble eukaryotic recombinant proteins in E. coli is favoured in early log-phase cultures induced at low temperature. SpringerPlus. https://doi.org/10.1186/2193-1801-2-89. Epub 2013 Mar 8

18. De Groot NS, Ventura S (2006) Effect of temperature on protein quality in bacterial inclusion bodies. FEBS Lett. https://doi.org/10.1016/j.febslet.2006.10.071

19. Sugahara KN, Teesalu T, Karmali PP, Kotamraju VR, Agemy L, Greenwald DR, et al (2010) Coadministration of a tumor-penetrating peptide enhances the efficacy of cancer drugs. Science. https://doi.org/10.1126/science.1183057

20. Tao Z, Shi A, Lu C, Song T, Zhang Z, Zhao J (2015) Breast cancer: epidemiology and etiology. Cell Biochem Biophys. https://doi.org/10.1007/s12013-014-0459-6

21. Takayama S, Ishii S, Ikeda T, Masamura S, Doi M, Kitajima M (2005) The relationship between bone metastasis from human breast cancer and integrin alpha(v)beta3 expression. Antican Res. 25: 79-84

22. Vasina JA, Baneyx F (1997) Expression of Aggregation-Prone Recombinant Proteins at Low Temperatures: A Comparative Study of the Escherichia coli csp Aandtac Promoter Systems. Prot Exp Pur. https://doi.org/10.1006/prep.1996.0678

23. Wang BL, Liang H, Zheng F, Li XX, Liu YB, Dai CL (2007) Recombinant soluble receptor activator of nuclear factor-kappaB inhibits parathyroid hormone-induced osteoclastogenesis in vitro. Sheng $\mathrm{Li}$ Xue Bao. https://doi.org/10.3892/mmr.2015.3407 Wen Z, Jia Q, Kang X, Lou Y, Zou L, Yang J, et al (2017) Antitumor activity of recombinant RGD-IFN-a2a-core fusion protein in vitro. Anti-cancer Drugs. https://doi.org/10.1097/CAD.0000000000000421

24. Winters S, Martin C, Murphy D, Shokar NK (2017) Breast cancer epidemiology, prevention, and screening. Prog Mol Biol Translation Sci. https://doi.org/10.1016/bs.pmbts.2017.07.002

25. Yang J, Wei Y, Yin H, Fang L, Chai D, Li H, et al (2019) Modification of IL-24 by tumor penetrating peptide iRGD enhanced its antitumor efficacy against non-small cell lung cancer. Int Immunopharmacol. . https://doi.org/10.1016/j.intimp.2019.02.027

26. Yan F, Wu H, Liu H, Deng Z, Liu H, Duan W, et al. (2016) Molecular imaging-guided photothermal/photodynamic therapy against tumor by iRGD-modified indocyanine green nanoparticles. J Cont Rel. https://doi.org/10.1016/j.jconrel.2015.12.050

27. Zhang Y, Yang J, Ding M, Li L, Lu Z, Zhang Q, et al (2016) Tumor-penetration and antitumor efficacy of cetuximab are enhanced by co-administered iRGD in a murine model of human NSCLC. Oncol Lett. https://doi.org/10.3892/ol.2016.5081

\section{Figures}


a

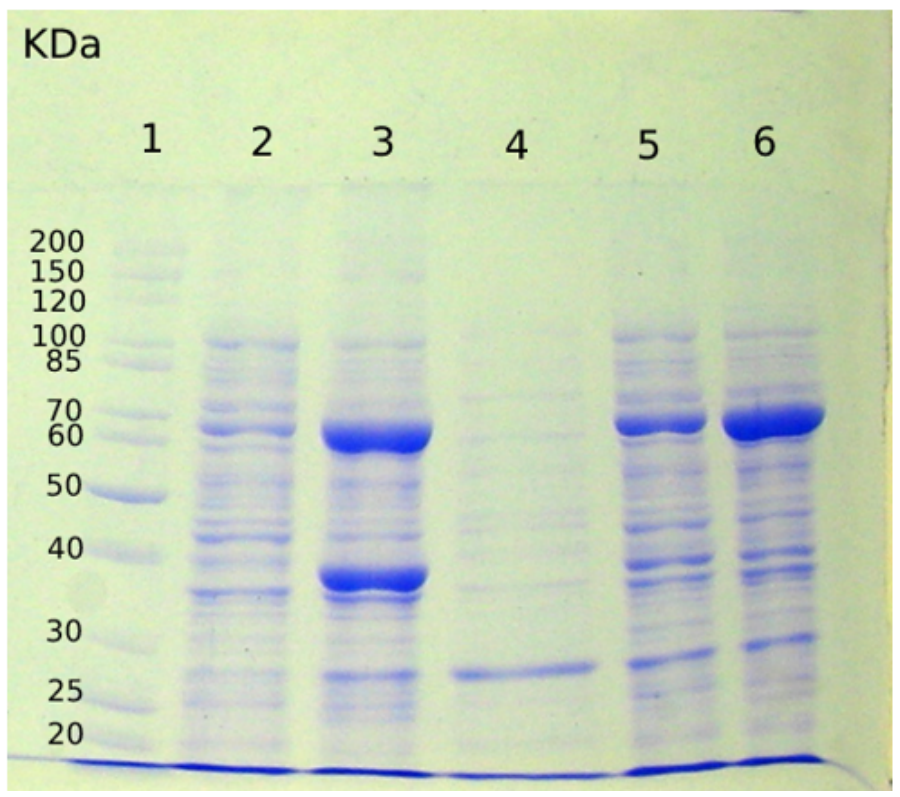

b

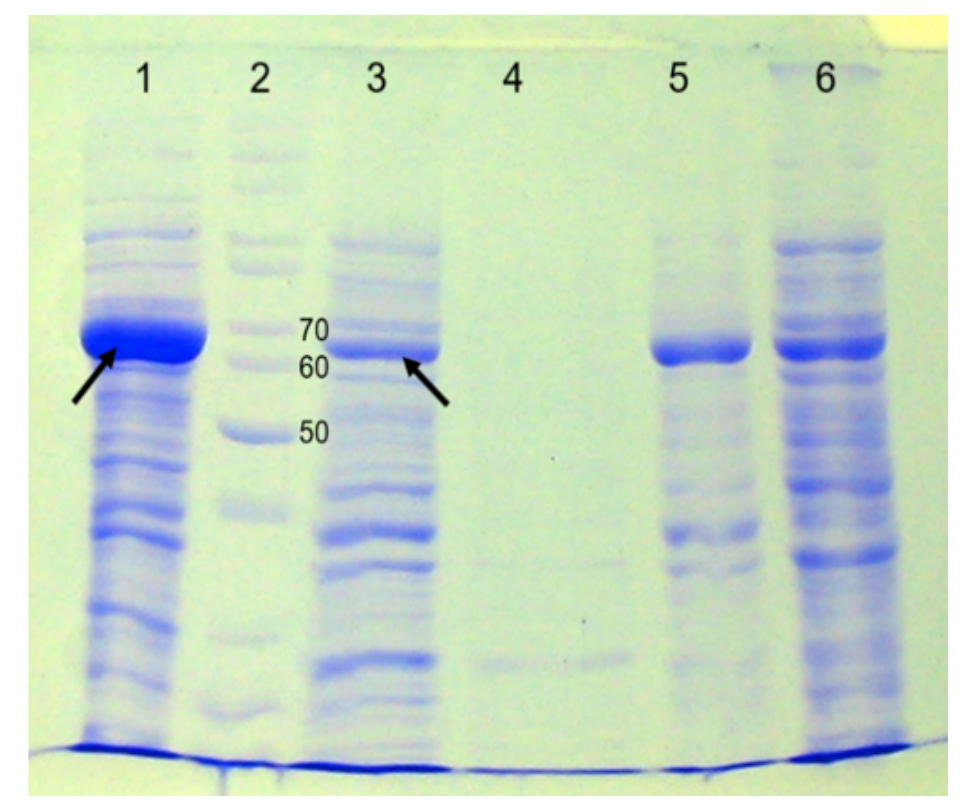

\section{Figure 1}

$12 \%$ SDS-PAGE a. analysis of DFF-40 expression. Lane 1: PageRuler ${ }^{\text {TM }}$ unstained protein ladder 26614 , Lane 2: un-induced E. coli BL21 (DE3) containing pTWIN1-DFF40, Lane 3: insoluble expression of induced E. coli BL21 (DE3) containing pTWIN1-DFF40, Lane 4: soluble expression of induced E. coli BL21 (DE3) containing pTWIN1-DFF40, Lane 5: total expression of induced E. coli BL21 (DE3) containing pTWIN1DFF40, Lane 6: total expression of induced E. coli BL21 (DE3) containing pTWIN1-DFF40 at $37^{\circ} \mathrm{C}$. b. analysis of DFF40-iRGD expression. Lane 1: total expression of induced E. coli BL21 (DE3) containing pTWIN1-DFF40-iRGD at $37^{\circ} \mathrm{C}$, Lane 2: PageRuler ${ }^{\mathrm{TM}}$ unstained protein ladder 26614, Lane 3: total expression of induced E. coli BL21 (DE3) containing pTWIN1-DFF40-iRGD at $15^{\circ} \mathrm{C}$, Lane 4: soluble expression of induced E. coli BL21 (DE3) containing pTWIN1-DFF40-iRGD, Lane 5: insoluble expression of induced E. coli BL21 (DE3) containing pTWIN1-DFF40-iRGD, Lane 6: un-induced E. coli BL21 (DE3) containing pTWIN1-DFF40-iRGD. 


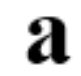

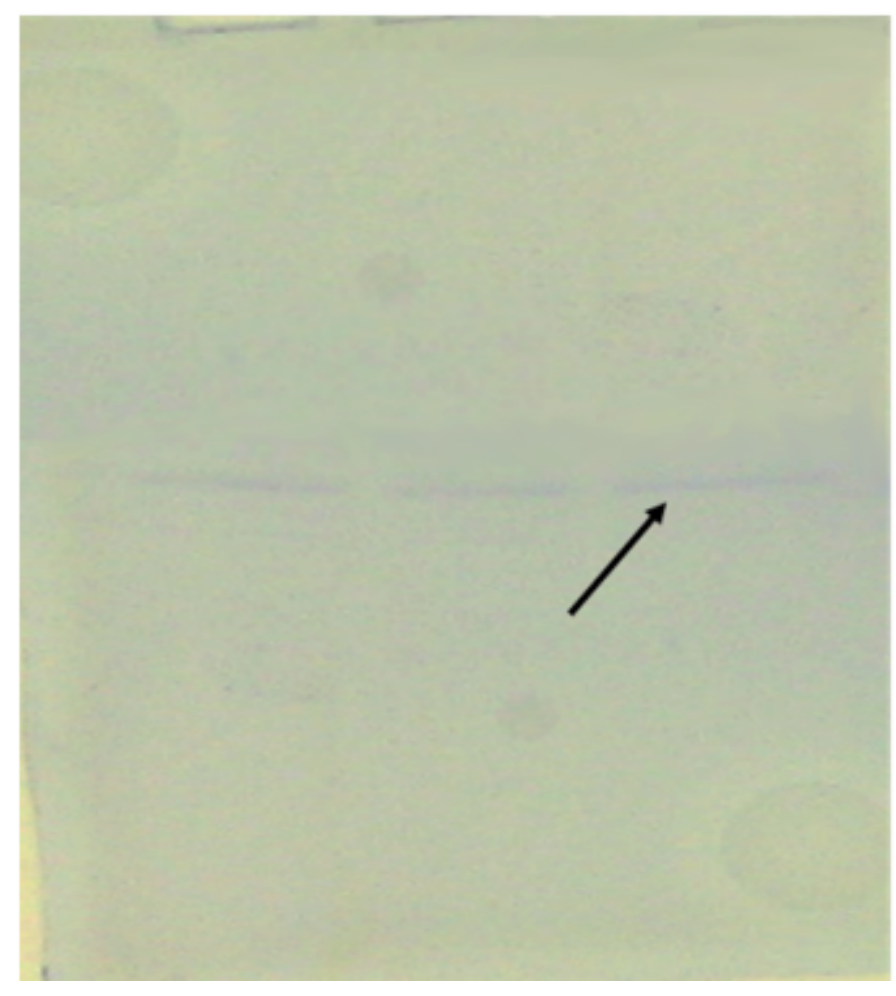

4

b

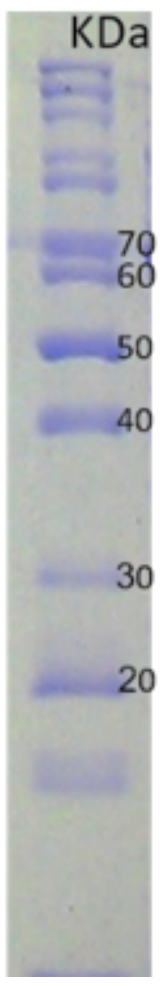

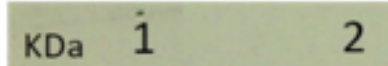

3

\section{Figure 2}

protein purification with IMPACT system. a. DFF40 purification. Lane 1: Third elution of the purified DFF40, Lane 2: Second elution of the purified DFF-40, Lane 3: First elution of the purified DFF-40, Lane 4: PageRulerm $^{\text {TM }}$ unstained protein ladder 26614. b. DFF40-iRGD purification. Lane 1: PageRuler ${ }^{\text {TM }}$ unstained protein ladder 26614, Lane 2: First elution of the purified DFF40-iRGD, Lane 2: Second elution of the purified DFF40-iRGD, Lane 3: Third elution of the purified DFF40-iRGD. 
a
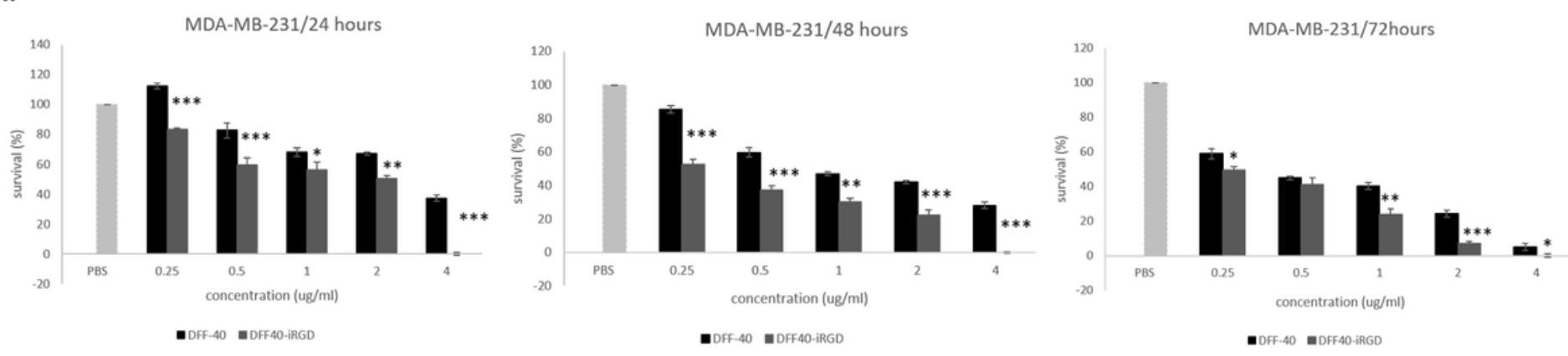

b
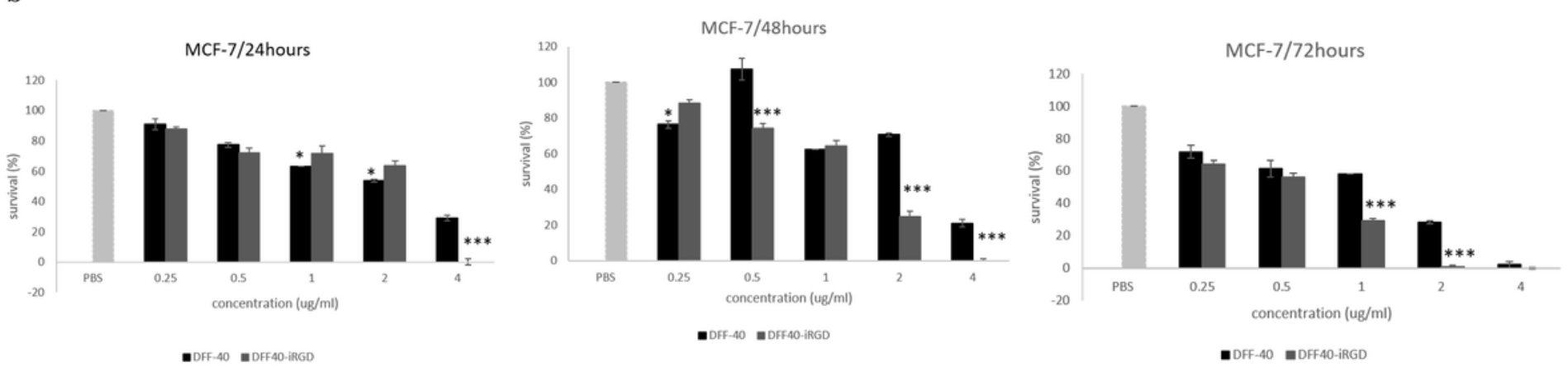

Figure 3

Cytotoxicity assays of DFF40 and DFF40-iRGD against different cell lines and various times. Error bars represent SD. stars were used to show the difference between two recombinant proteins effects in the same concentrations.
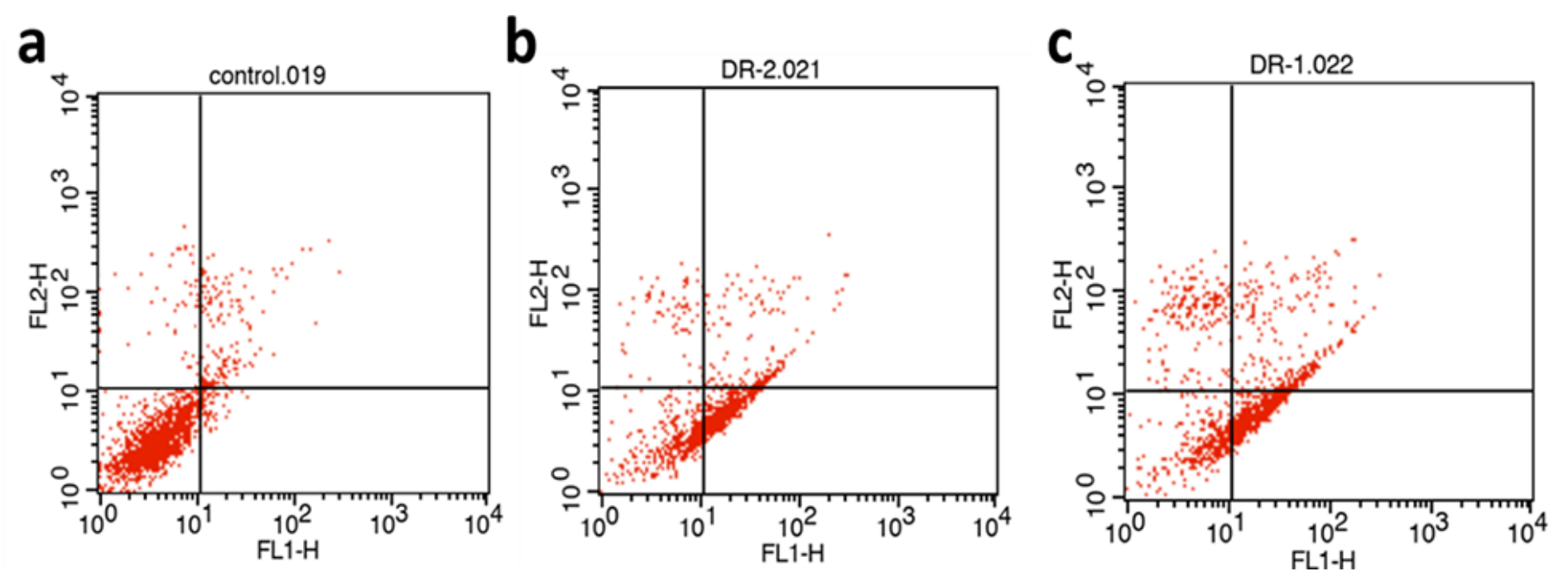

Figure 4

confirming the apoptosis induction by flowcytometry. a: un-treated control cells after 24 hours of incubation. b: cells treated with $0.25 \mu \mathrm{g} / \mathrm{ml}$ of DFF40-iRGD. c: cells treated with $0.5 \mu \mathrm{g} / \mathrm{ml}$ of DFF40-iRGD Lower Left: live cells (annexin V-/ PI-); Lower Right: early apoptotic cells (annexin V+/ PI-); Upper Left: dead cells (annexin V-/ PI+); Upper Right: late apoptotic cells (annexin V+/ PI+). 